\title{
As mestras do barro: a arte das louceiras no Semiárido da Paraíba, Nordeste do Brasil
}

\section{Ana Paula Gonçalves Leite ${ }^{1},{ }^{*}$, Adriana de Fátima Meira Vital $^{2}$, Camilla Marques de Lucena ${ }^{3, *}$ e Reinaldo Farias Paiva de Lucena ${ }^{3}$,**}

${ }^{1}$ Universidade Federal da Paraíba. Centro de Ciências Exatas e da Natureza. Programa de Pós-Graduação em Desenvolvimento e Meio Ambiente - PRODEMA. João Pessoa-PB, Brasil (CEP 58051-900). *E-mail: paulagleite1@gmail.com.

${ }^{2}$ Universidade Federal de Campina Grande. Centro de Desenvolvimento Sustentável do Semiárido. Sumé-PB, Brasil (CEP 58540-000).

${ }^{3}$ Universidade Federal do Mato Grosso do Sul. Instituto de Biociências. Laboratório de Etnobotânica. Campo Grande-MS, Brasil (CEP 79070-900). *E-mail: camilla.lucena@ufms.br; **E-mail: reinaldo.lucena@ufms.br.

Resumo. Um dos espaços mais prósperos para estudos etno-pedológico e ecológico é a utilização dos solos para atividades artesanais. Vários estados brasileiros registram uma grande produção de objetos em barro, porém, essa cultura não tem recebido atenção apropriada. 0 objetivo da pesquisa é registrar e analisar o conhecimento das mulheres louceiras da Comunidade Ligeiro de Baixo, Serra Branca, Paraíba, Brasil, sobre o uso do solo para fins artesanais, identificando as políticas públicas de apoio e incentivo, seu impacto para as louceiras e as dificuldades no processo da coleta, produção e comercialização. Os dados foram coletados por observação direta, entrevista semiestruturada e diálogo informal. Foram entrevistadas seis louceiras. Ainda que detenham o conhecimento dos mais experientes, a nova geração não demonstra interesse na continuidade da atividade sobretudo pela desvalorização cultural, político-social e econômica. Tornam-se urgentes gestões mais participativas e ações em educação e cultura para o despertamento da sociedade, e a preservação desse conhecimento tradicional que traduz toda história de um povo.

Palavras chave: Louceiras; Barro; Etnopedologia; Políticas públicas.

Abstract. The clay masters: The art of clay pottery in the SemiArid Region of Paraíba, Northeast Brazil. One of the most prosperous spaces for ethno pedological and ecological studies is the use of soils for handicraft activities. Several Brazilian States record a large production of clay objects, however this culture has not received appropriate attention from public management. Thus, the goal of this research is to register and analyze the knowledge of crockery maker women in the Community of
Recebido

$08 / 06 / 2021$

Aceito

$30 / 08 / 2021$

Publicado

$31 / 08 / 2021$

Acesso aberto

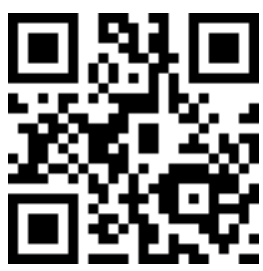

ORCID

(1) 0000-0002-1820-8307 Ana Paula Gonçalves Leite

(D) 0000-0001-9936-8347 Adriana de Fátima Meira Vital

(ㄱ) 0000-0002-5126-8969 Camilla Marques de Lucena

ISSN 2359-1412/RBGAS-2021-0096/2021/8/19/40/1239 
Ligeiro de Baixo, Municipality of Serra Branca, State of Paraíba, Northeast Brazil, about the use of soil for commercial purposes, identifying the public policies of support and incentive, its impact for the crockery makers and difficulties in the collection, production and marketing process. Data were collected by direct observation, semi- structured interview and informal dialogue. Six crockery makers were interviewed. Although retaining the knowledge of the most experienced, the new generation shows no interest in the continuity of the activity, mainly due to cultural, political-social and economic devaluation. More participatory management becomes urgent, as well as actions in education and culture, for the awakening of society and the preservation of this traditional knowledge that translates the whole history of a people.

Keywords: Crockery makers; Clay; Ethnopedology; Public policies.

\section{Introdução}

Buscando despertar o interesse das novas gerações, e a responsabilidade da gestão pública, no presente estudo buscamos empoderar a sociedade e a academia científica com conhecimentos sobre as louceiras do semiárido do Nordeste do Brasil, mulheres que tem por atividade econômica a produção de diversos artefatos com a utilização de solo, sendo também conhecidas como artesãs. Nesse sentido, estamos colaborando para preservar a história cultural da arte com barro que elas desenvolvem, e vem sendo transmitida ao longo das gerações.

Conhecer as populações locais e suas percepções sobre o solo, possibilita a caracterização e descrição do seu uso e manejo por aqueles que usam localmente esse recurso, contribuindo para o desenvolvimento da ciência do solo, e fornecendo subsídios para um esboço de sistemas adaptados à realidade local, tornando-se um instrumento de valorização do patrimônio sócio-cultural (Cabral, 2011).

Um dos espaços mais prósperos para estudos de etnoecologia, quer seja pedológico ou ecológico, é a utilização dos solos para atividades artesanais (Barrera-Bassols e Toledo, 2005). Existe uma grande produção de objetos em barro ocorrendo em vários Estados brasileiros, sobretudo com temática religiosa, decorativa e utilitária, porém sem grande ou nenhuma visibilidade (Borges, 2017; Turchetti, 2018), e, nesse sentido, a abordagem da etnopedologia pode contribuir significativamente em ações voltadas para políticas públicas com foco nesses agentes sociais, as louceiras e outros artesãos do barro.

Através da abordagem etnopedológica as pesquisas sobre o saber das populações locais sobre os solos podem colaborar de forma robusta na compreensão dessa relação, isso porque, a etnopedologia objetiva, dentre outras coisas, analisar "e entender as interfaces existentes entre os solos, a espécie humana e os outros componentes dos ecossistemas" (Alves, 2005). "Porém, informações coletadas junto às populações locais e a maneira como utilizam o solo, estão mais ligadas ao desenvolvimento da ciência formal. $\mathrm{Na}$ Ciência do Solo, o exemplo mais importante talvez esteja nos levantamentos realizados por Vasili Dokuchaev, que influenciaram a classificação de solos em muitos países" (Krasilnikov e Tabor, 2003).

Cabral (2011) argumenta que "por meio de investigações etnopedológicas é possível caracterizar e descrever o uso e manejo do solo sob a perspectiva daqueles que usam localmente esses recursos, possibilitando vultosas contribuições para o desenvolvimento da 
ciência do solo, além de fornecer subsídios para o delineamento de sistemas adaptados à realidade local. Além disso, poderá ser um instrumento para a valorização do patrimônio sócio-cultural relativo ao saber camponês sobre os solos".

Para Minami (2009), "o solo possibilitou e promoveu uma grande variedade de culturas, civilizações e modos de vida ao longo da história". No contexto cultural, Houaiss e Vilar (2001) "atribuem acepções relacionadas ao aspecto antropológico, mas também ligadas ao manejo do solo, de plantas e animais. Diante disso, percebe-se que o solo pode ser considerado não só como um corpo natural, mas também como um corpo sócio-cultural."

De maneira mais específica, Alves (2005) mostra o conhecimento sofisticado e integrado das ceramistas paraibanas, que produzem arte com o solo. Dentre elas estão as louceiras de Ligeiro de Baixo, comunidade rural do Município de Serra Branca, região do Cariri, localizado na Paraíba, no nordeste do Brasil. Essas mulheres modelam o barro utilizando produtos, técnicas e metodologias com fins de transformação social, realizando um processo de baixo custo e mínimo impacto ambiental, colaborando para organização da comunidade com desenvolvimento da criatividade e a elevação da autoestima dos envolvidos, além de proporcionar elevação de sua renda (Vital e Santos, 2017).

A profissão de Artesão é oficialmente reconhecida no Brasil pela Lei no 13.180/2015 e defende, dentre suas diretrizes, "a qualificação permanente e o estímulo ao aperfeiçoamento dos métodos e processos de produção, o apoio comercial, a certificação da qualidade do artesanato, agregação de valor aos produtos e suas técnicas artesanais e a divulgação do artesanato" (Brasil, 2015), dentre outras não menos relevantes.

De acordo com a Base Conceitual do Artesanato Brasileiro, definida na Portaria $\mathrm{n}^{\mathrm{o}}$ 29/2010, o artesanato tradicional configura-se como o conjunto de artefatos expressivos da cultura de um determinado grupo, representando suas tradições incorporadas à vida cotidiana como parte indissociável de seus usos e costumes. A produção originária da família ou da comunidade, favorece a transferência de conhecimento e técnica, e o seu valor cultural dá-se pela preservação e memória dessa comunidade (Brasil, 2010).

Ainda que acomodadas na categoria de artesão, por meio da Lei no 13.180/2015 (Brasil, 2015), as louceiras do semiárido paraibano não recebem nenhum tipo de orientação, qualificação, estímulo, aperfeiçoamento de métodos, apoio comercial, nem divulgação de sua arte por parte da gestão pública.

Expandir as oportunidades individuais, institucionais e regionais, é função primordial de uma gestão pública contemporânea (Matias-Pereira, 2010), desde que os gestores compreendam que governar supera o cumprimento aos princípios básicos da administração pública, ultrapassando os padrões internos, exigindo uma visão multidisciplinar dos campos da Ciência Política, Administração, Economia, Contabilidade, Sociologia, Direito, Meio Ambiente, Cultura e Turismo (Kickert e Stillmann, 1999).

Nesse cenário, esta pesquisa busca registrar e analisar o conhecimento das mulheres louceiras da Comunidade Ligeiro de Baixo, no município de Serra Branca, no Estado da Paraíba, no nordeste do Brasil, sobre o uso do solo para fins artesanais, identificando as políticas públicas e dificuldades envolvidas nesse processo. Especificamente, busca registrar o uso dos solos pelas louceiras de barro, descrever o processo de coleta e comercialização das louças, identificar os tipos de louças produzidas e seu destino final, por fim, registrar e avaliar as políticas públicas direcionadas à essa prática e seus impactos para as louceiras, buscando agregar valor e o interesse da sociedade, empoderando-a dos conhecimentos tradicionais e preservando a sua história cultural. 


\section{Material e métodos}

\section{Área de estudo}

0 estudo foi realizado na Comunidade Rural Ligeiro de Baixo, distando $7 \mathrm{~km}$ da sede do Município de Serra Branca, localizado na região semiárida, Mesorregião da Borborema e Microrregião do Cariri Ocidental no Estado da Paraíba, 07² 29' 00" S e 36³9' 54" W, com 493 m acima do nível do mar (IBGE, 2017).

Ainda, segundo o IBGE (2017), sua população é de 13.707, sendo 7.018 (51,2\%) feminina e 6.689 (48,8\%) masculina. Distando 231,5 km de João Pessoa, capital do Estado. Possui uma área territorial de 704,6 km², e limita-se com os municípios de Sumé (32 km), Coxixola (18 km), São José dos Cordeiros (19 km), Parari (18 km) e São João do Cariri $(17,5 \mathrm{~km})$.

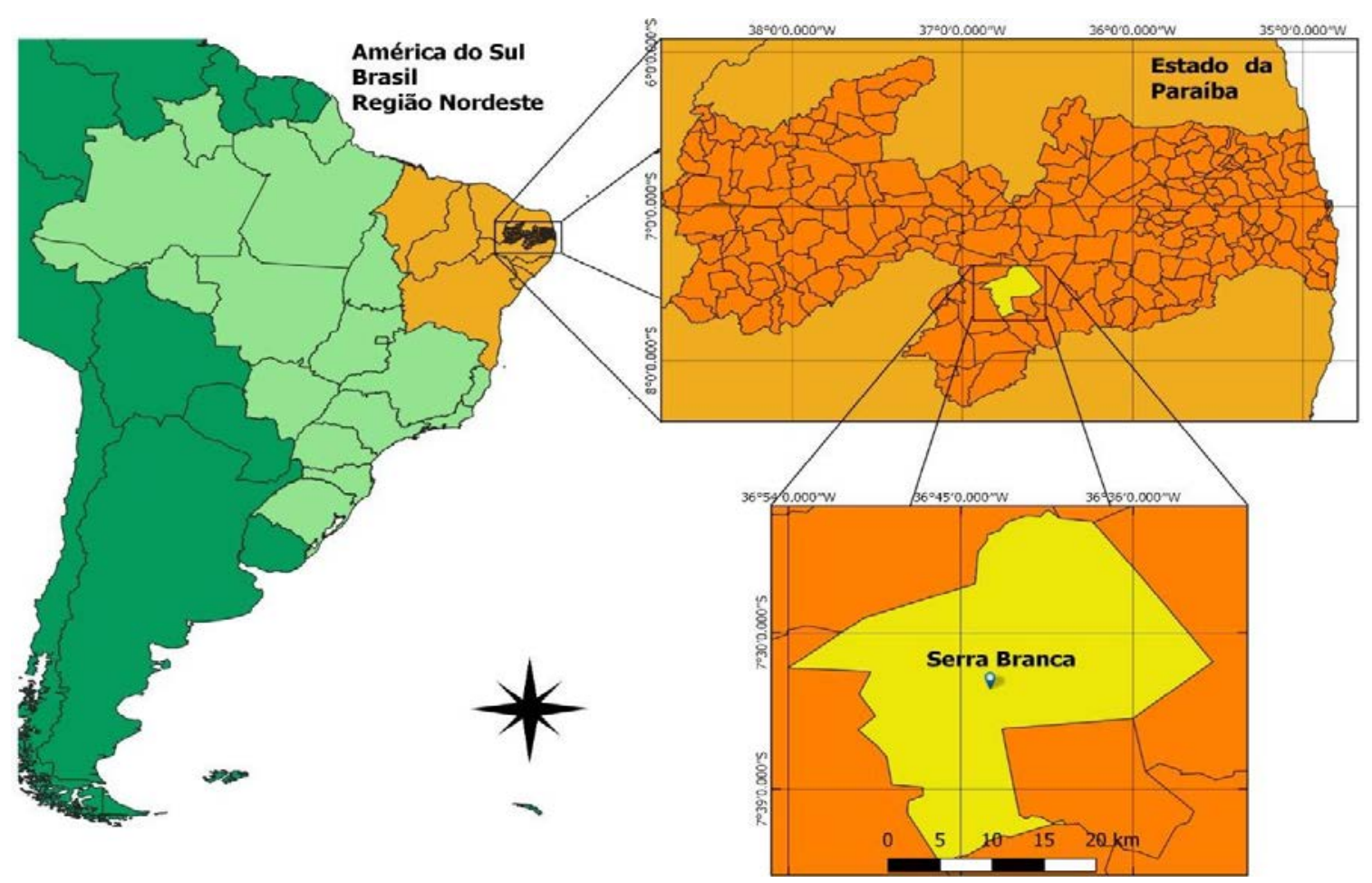

Figura 1. Localização do Município de Serra Branca, Paraíba, Nordeste do Brasil.

De clima semiárido quente, a temperatura anual oscila entre $18{ }^{\circ} \mathrm{C}$ e $35^{\circ} \mathrm{C}$, apresentando, predominantemente, uma vegetação de caatinga, variando entre hiperxerófila e arbustiva aberta, com presença de plantas espinhosas, cactáceas e bromeliáceas. 0 relevo apresenta forma ondulada e ondulada suave, com declives variando entre $2 \%$ e $12 \%$, vertentes longas e índice erosivo acentuado em virtude da ação antrópica. A sudoeste da área estudada, o relevo é ondulado e forte ondulado, possuindo alguns pontos montanhosos (Brasil, 1972). De acordo com o Sistema Brasileiro de Classificação do Solo (EMBRAPA, 2013), os solos da região são classificados como: Luvissolo com manchas, Vertissolo, Neossolo, Argissolo e Afloramentos de rochas.

Sua principal atividade econômica é a agropecuária, com predominância do cultivo e colheita de feijão, milho, melancia, tomate e batata doce (agricultura), e efetivo de caprinos, ovinos, galinhas (e seus derivados), peixe/tilápia e bovino (e seus derivados), na pecuária (IBGE, 2017). 


\section{Público-alvo e amostragem}

A pesquisa foi realizada com $100 \%$ (seis mulheres) das louceiras residentes na comunidade rural Ligeiro de Baixo. A seleção ocorreu pelo Método Bola de Neve (snow ball) (Bailey, 1994), incidindo em uma amostragem não-probabilística (Albuquerque et al., 2010), selecionando o público-alvo de forma intencional. 0 primeiro contato aconteceu na companhia de um grupo de alunos do curso de Agroecologia do Campus CDSA/UFCG (Sumé, Paraíba) que participaram de uma aula de campo sobre o tema (solo).

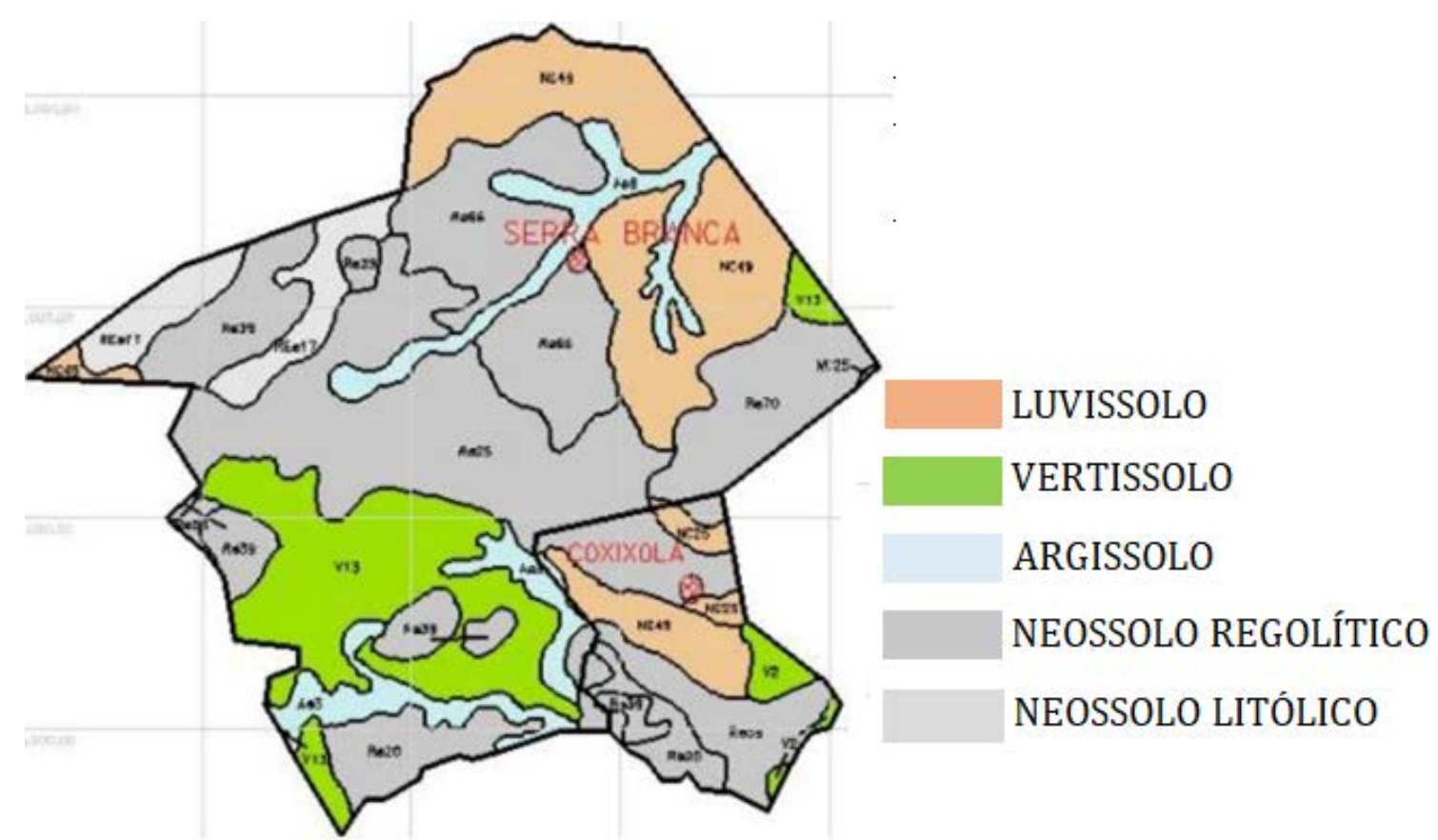

Figura 2. Mapa de classificação dos solos da região do município de Serra Branca, estado da Paraíba, nordeste do Brasil. Fonte: Brasil (1972), Paraíba (1978), adaptado.

A intenção foi estabelecer um diálogo informal e uma relação de confiança, não somente com as mulheres louceiras mas com toda a família. As visitas posteriores iniciaram com a louceira com maior idade (91 anos), Dona Quitéria, tendo seguimento com as demais da comunidade: Raimunda, 84 anos; Elisabeth, 67 anos; Maria José, 59 anos; Maria de Fátima, 56 anos e Vera Lúcia, 49 anos, todas de famílias de agricultores, sempre acessíveis, cordiais e dispostas a contribuir com a pesquisa, e dividir as suas histórias de vida na lida diária e apaixonada pela arte com o barro.

Esse grupo específico foi selecionado por aglomerar o maior número de louceiras em um espaço geográfico, além de pertencerem a mesma família, em menor ou mais elevado grau de parentesco. Todas foram esclarecidas sobre a pesquisa e a necessidade de autorização da participação, assinando o Termo de Consentimento Livre Esclarecido TCLE, aprovado pelo Comitê de Ética em Pesquisa da Universidade Federal da Paraíba (UFPB) (CEP/UFPB no 2.613.549), conforme estabelece a Resolução no 466/2012, do Conselho Nacional de Saúde (Brasil, 2012).

\section{Metódos e técnicas}

Inicialmente, utilizou-se a observação direta (Albuquerque et al., 2010) afim de conhecer os métodos de coleta, reconhecimento, preparação, confecção e queima do solo. Concomitante a observação, foram realizadas as entrevistas com uso de gravador e de formulário semi-estruturado (Huntington, 2000) dividido em três partes. A primeira parte 
abordou questões referentes ao perfil socioeconômico das entrevistadas (idade, sexo, escolaridade, ocupação, estado civil e quantidade de filhos). Na segunda foram solicitadas informações sobre o reconhecimento do solo, a confecção das peças (reconhecimento, método de coleta e preparo do barro). Já na terceira, aplicamos perguntas sobre gestão e políticas públicas (armazenamento, transporte, comercialização e apoios). Foram visitados e registrados fotograficamente, todos os locais do processo, desde a escolha do barro à comercialização.

Os materiais utilizados para coleta e registro das informações foram: papel ofício A4 cor branco, caneta esferográfica azul, gravador de voz (Panasonic RR-US551) e máquina fotográfica para registro de imagens (celular LG K10 2017 e Iphone 6s Apple 2015), compreendendo o horário entre $07 \mathrm{~h} 00$ e $12 \mathrm{~h} 00$. Foram realizadas visitas no período entre setembro de 2017 e setembro de 2018.

\section{Resultados e discussão}

\section{Características socioeconômicas das Louceiras}

Foram entrevistadas seis louceiras (100\%) na comunidade Ligeiro de Baixo de Serra Branca (Tabela 3). Das seis entrevistadas, três (50\%) ultrapassam os 60 anos, enquadrando-se como idosas, de acordo com a faixa de idade estabelecida pelo Estatuto do Idoso (Brasil, 2003). Todas (100\%) são naturais de Serra Branca e são alfabetizadas, pelo menos até o $5^{\text {o }}$ ano do ensino fundamental. Cinco delas $(83,5 \%)$ são aposentadas como agricultoras rurais e não dependem exclusivamente da louça de barro para subsistência, enquanto que uma $(16,5 \%)$ depende exclusivamente da atividade para sobreviver. Quanto aos filhos, todas são mães, com filhos predominando o gênero masculino $(62,5 \%)$ sobre o feminino $(37,5 \%)$, esse contexto pode aprsentar interferência na manutenção do saber e da arte do barro, já que é, em sua maioria, uma atividade predominantemente femina.

Tabela 3. Características socioeconômicas das louceiras da Comunidade Ligeiro de Baixo, Serra Branca, Paraíba, Brasil.

\begin{tabular}{|c|c|c|}
\hline Aspectos sociais & Números de entrevistados & Frequência relativa (\%) \\
\hline \multicolumn{3}{|l|}{ Idade } \\
\hline 40 a 60 anos & 3 & $50,00 \%$ \\
\hline$>60$ anos & 3 & $50,00 \%$ \\
\hline \multicolumn{3}{|c|}{ Escolaridade (alfabetizadas) } \\
\hline Sim & 6 & $100,00 \%$ \\
\hline \multicolumn{3}{|l|}{ Naturalidade } \\
\hline Serra Branca-PB & 6 & $100,00 \%$ \\
\hline \multicolumn{3}{|l|}{ Ocupação } \\
\hline Dona de casa e louceira & 1 & $16,50 \%$ \\
\hline Aposentada & 5 & $83,50 \%$ \\
\hline \multicolumn{3}{|c|}{ Tempo de atividade/louceira (anos) } \\
\hline 10 a 30 & 0 & $0,00 \%$ \\
\hline$>30$ & 6 & $100,00 \%$ \\
\hline \multicolumn{3}{|l|}{ Filhos } \\
\hline Sim & 6 & $100,00 \%$ \\
\hline Não & 0 & $0,00 \%$ \\
\hline \multicolumn{3}{|l|}{ Gênero dos filhos } \\
\hline Feminino & 6 & $37,50 \%$ \\
\hline Masculino & 10 & $62,50 \%$ \\
\hline
\end{tabular}


Embora desenvolvam a atividade remunerada com barro há mais de 30 anos, não a consideram como uma profissão, e destacam que, hoje, as peças de barro contribuem muito pouco com a renda familiar, exceto uma das entrevistadas (Figura 4), que sobrevive exclusivamente da comercialização das obras de barro, porém aguarda pela aposentadoria. Quase 84\% delas reconhecem na aposentadoria a principal fonte de renda.

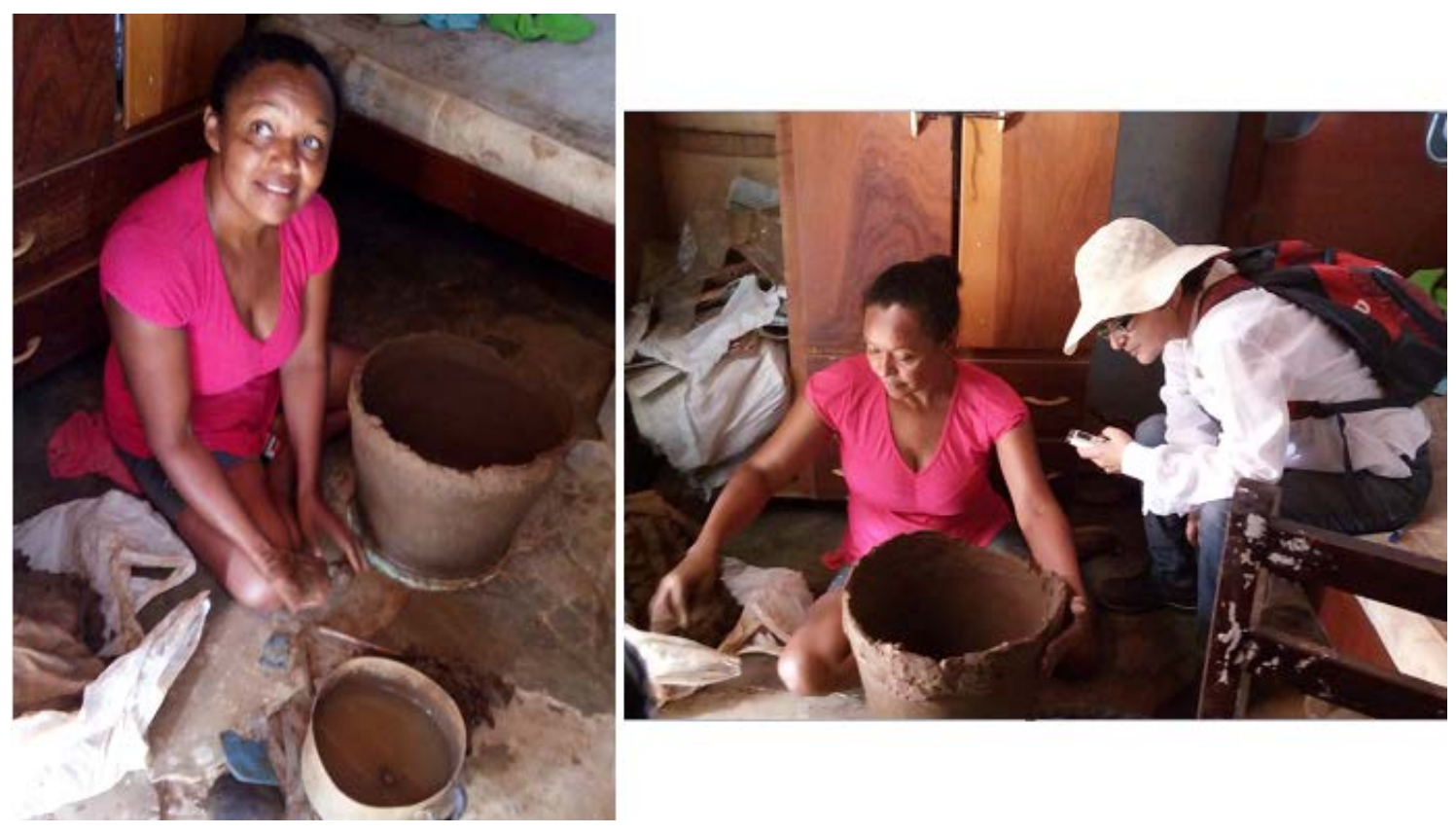

Figura 4. Vera Lúcia, única louceira a sobreviver, exclusivamente, da louça de barro na comunidade Ligeiro de Baixo, Serra Branca, Paraíba, Brasil.

Nesse quesito, as gestões e demais instituições interessadas na disseminação do conhecimento tradicional, podem articular bolsas de incentivo para os candidatos à aprendizes, bem como, para as louceiras interessadas em ministrar cursos e oficinas, considerando que "o conhecimento é uma gama de diferentes formas e dimensões do saber humano, e que é necessário, de qualquer maneira e sempre conhecer, o tempo todo, está realizando a ousadia e o esforço de adquirir mais e melhor conhecimento" (Brandão, 1997), copiando prática bem sucedida de bolsas subsidiadas pela gestão do município de Sumé (cerca de $30 \mathrm{~km}$ de Serra Branca), no Estado da Paraíba que, por meio de Decreto Municipal no 340/1991 (Serra Branca, 1991), incentiva jovens do município à prática de música junto à Filarmônica Municipal "Maestro Antônio Josué de Lima", exemplo que poderia ser seguido contribuindo com os artesãos de barro e outras materias primas.

Constatou-se que a arte com o barro ocupa espaço nos domicílios e compartilha a atenção com as tarefas domésticas e agropecuárias, e que $100 \%$ das entrevistadas tem filhos (16 no total), todos, segunda as próprias, alimentados, vestidos e educados por meio da atividade com barro, alguns inclusive com ensino superior. Contudo, nenhum desses filhos demonstra interesse na continuidade da arte com o barro, ainda que detenham o conhecimento e contribuam de alguma forma com suas mães.

Provavelmente, a predominância masculina nos filhos influência nessa realidade, pois, respaldando-se em Almeida (2003) e Cabrera-Garcia (1996) "há uma tendência na qual a modelagem artesanal da cerâmica utilitária é feita por mulheres, com participação minoritária de homens". Eles até conhecem as técnicas e sabem como fazer, mas preferem colaborar na coleta e transporte do barro e da lenha, na queima das peças maiores e no 
transporte até as feiras livres, estabelecendo, de certa forma, um critério de força e habilidade, de modo que, as atividades que exigem mais força física sejam exercidas pelos homens e aquelas que exigem mais delicadeza e precisão, como a confecção e acabamento das peças, exercidas pelas mulheres.

Quanto as filhas mulheres, as louceiras afirmam, de maneira coletiva, que elas sabem confeccionar melhor que as mães e com mais "capricho", mas não se dispõe, seja pelo "sacrifício" físico, reconhecimento cultural e/ou, principalmente, pelo retorno econômico/financeiro. Mesmo diante desse posicionamento da nova geração, a louceira mais idosa em atividade (Quitéria, 91 anos) diz que não optaria por outra vida, "escolheria o barro novamente. Com ele sou feliz".

Nesse sentido, Santos (2010) esclarece que a categoria gênero é determinante nas relações que são construídas em torno do trabalho do barro, e, no contexto "relações", Maria de Fátima (56 anos) emociona-se ao dizer que "reconhece no barro um bom coração e que ele nunca lhe faltou, nunca lhe decepcionou".

Embora as entrevistas com as mulheres tenha predominado, os homens da família contribuíram complementando as informações e apresentando alternativas simples de convivência das louceiras e suas dificuldades, a exemplo de Francisco, esposo de Maria de Fátima que, preocupado com as condições de saúde da esposa e considerando o apego à atividade de barro, desenvolveu um equipamento que possibilita o manuseio rotativo da louceira com a peça de barro, sentada e apoiada com os pés no chão, evitando as dores lombares (Figura 5).
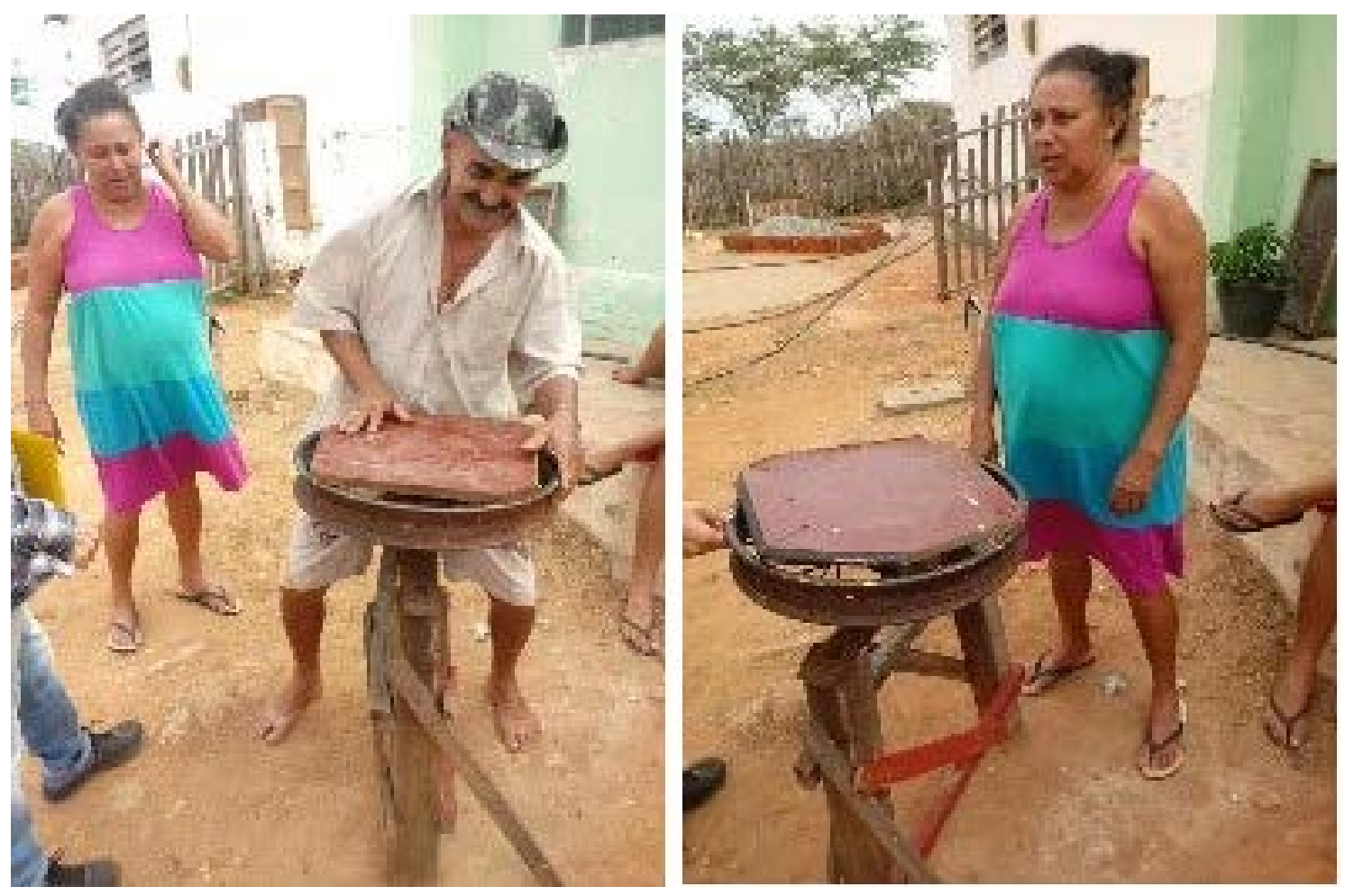

Figura 5. Equipamento desenvolvido pelo senhor Francisco, esposo da louceira Maria de Fátima residente da comunidade Ligeiro de Baixo, Serra Branca, Paraíba, Brasil.

\section{Processo produtivo}

Utiliza-se para constituir o corpo das peças de barro a água e uma mistura de materiais de solo (terra e barro). Para proteção da superfície utiliza-se galhos e restos de 
plantas e pedaços de tecido. Para a queima, usa-se lenha de diferentes portes e espécies vegetais. Na comundiade estudada, a decoração das peças não é comum entre louceiras.

O bom barranco, como são chamados pelas louceiras, é o local que contém o material apropriado para confecção da peça de barro, e situam-se em ambientes distintos nem sempre próximos às residências das louceiras, por vezes, em propriedade particular.

A frequência da coleta varia de acordo com o regime das chuvas, condições do solo, demanda do barro pelas louceiras, e disponibilidade de mão de obra para a coleta. A água oriunda de barragens e/ou cisternas nas próprias residências, é utilizada em diferentes etapas do processo produtivo: para a mistura do barro, durante a modelagem e também no processo de tratamentos.

O barro, quando coletado e transportado, é depositado em forma de "montes", em cômodos das residências e cobertos por lonas plásticas ou pedaços de pano velhos por um período de 24 a 48 horas, até que seja quebrado e umedecido/aguados. Antes de agoar com água, os barros são quebrados em pedaços menores e peneirados a fim de separar os demais materiais de solo.

Após molhado o barro, as louceiras retiram porções denominadas de "bolos", de tamanho proporcional à peça que vai ser confeccionada. Esse bolo é posto em uma superfície plana umedecida, até que é feito um "furo" com o dedo indicador ou é aberto um espaço oco através do bolo, com a mão fechada. Por meio de movimentos em sentido ascendente e circular utilizando os dedos e apoiando o vaso em construção com a outra mão, a louceira vai reduzindo a espessura da parede do bolo de barro e vai dando forma a peça. Quando é formado um vaso oco, iniciam-se outros movimentos em sentido tendencioso para reduzir o diâmetro da abertura superior do vaso.

Após a última etapa de secagem, os vasos estão prontos para a queima. A atividade é exercida, não exclusivamente, mas principalmente, por homens. As peças são posicionadas no forno com a boca voltada para baixo. Em seguida, são cobertas com pedaços de peças de barro quebradas (cacos), protegendo a peça da área externa do forno, isso porque, se houver interferência do vento, a peça pode rachar e, conforme assinalam, "pipocar".

Quanto à queima, esquentar, significa o início do calor ao forno, quando se dá preferência aos galhos de plantas mais finos e de mais fácil queima, também chamados de "garrancho", adquiridos perto das residências das louceiras. Em seguida, são colocados pedaços de madeira de maior espessura para formar as "lavaredas". Quando a cinza começa a se formar, tem início o trabalho de esfriar, que, nada mais é, do que diminuir lentamente a temperatura do forno, retirando a lenha queimada ou diminuindo sua adição. A queima dura cerca de duas a três horas, do início ao fim do processo. A retirada dos vasos queimados se dá, na maioria dos casos, após o resfriamento completo que ocorre, cerca de 12 horas após o início da queima, ao ar livre.

\section{Descontinuidade da atividade: dificuldade}

Nota-se que, a ausência de sucessores causa certo desalento e tristeza nas entrevistadas que reconhecem a desvalorização da atividade artesanal com o barro enquanto gerador de trabalho e renda. Alguns autores corroboram essa compreensão sobre as mudanças no estilo de vida, acrescentando que "as interferências causadas pelas redes sociais, tem provocado redução no tempo de vivência das novas gerações com os familiares mais antigos", e que, a redução na transmissão desses conhecimentos pode se tornar um futuro processo de aculturação (Carvalho, 2012).

Contudo, além da ausência de valorização e interesse dos mais jovens, outras variáveis (Figura 6), contribuem para fragilização e provável interrupção na história dessas louceiras de barro. 


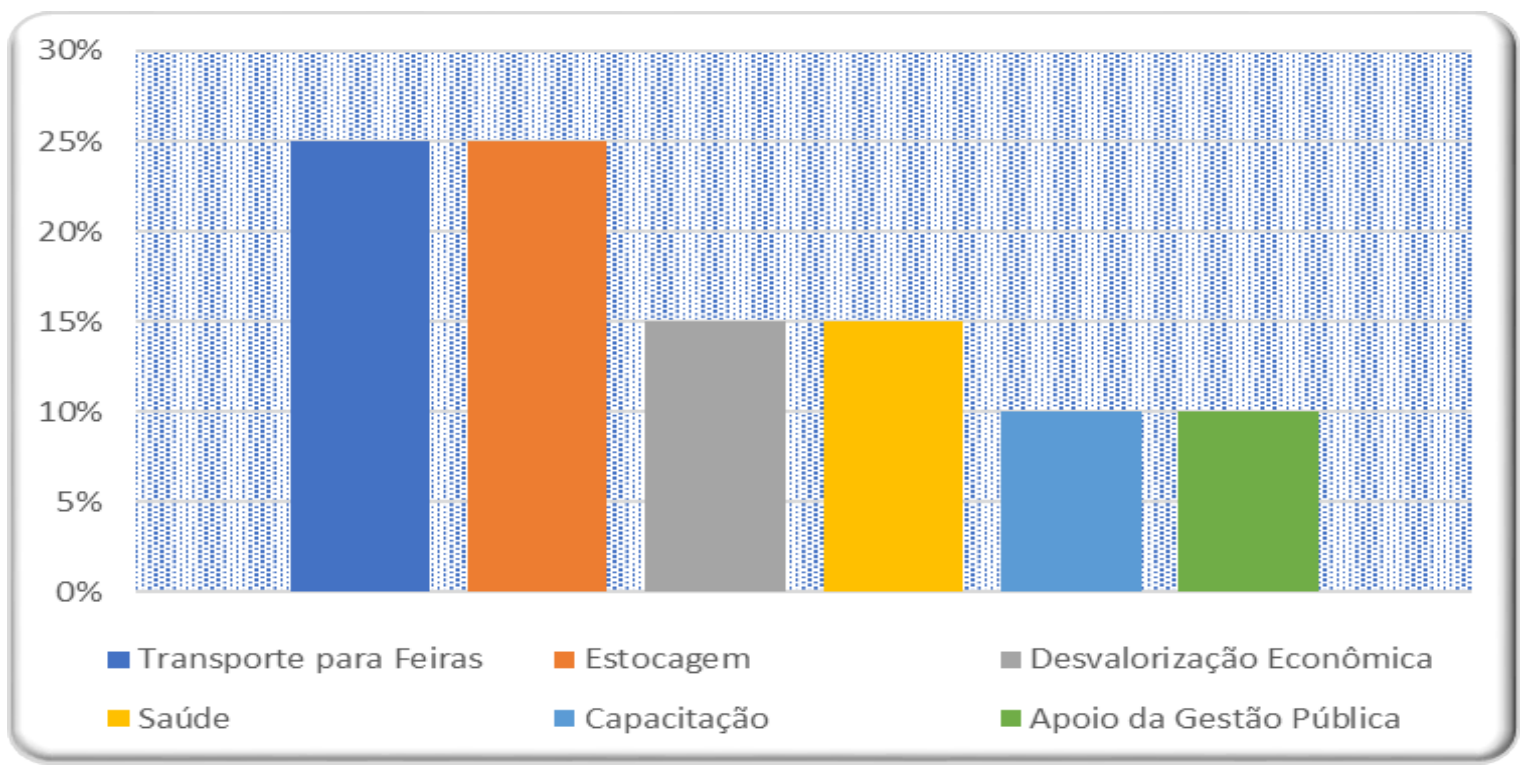

Figura 6. Variáveis que limitam a continuidade do artesanato com louça de barro na comunidade Ligeiro de Baixo, Serra Branca, Paraíba, Brasil.

Observa-se que o transporte para as feiras e a estocagem constituem o maior empecílho para comercialização, fato registrado na Figura 7. Isso porque, necessitam custear o combustível e o aluguel do espaço onde as peças ficam alojadas nos locais das feiras, visto que, como residem na zona rural, o translado semanalmente, desgasta, tanto as louceiras quanto as peças que, por vezes se quebram. 0 custeio para manutenção da atividade, é retirado das suas aposentadorias e, por vezes, as vendas e lucros não cobrem as despesas causando-lhes prejuízos.

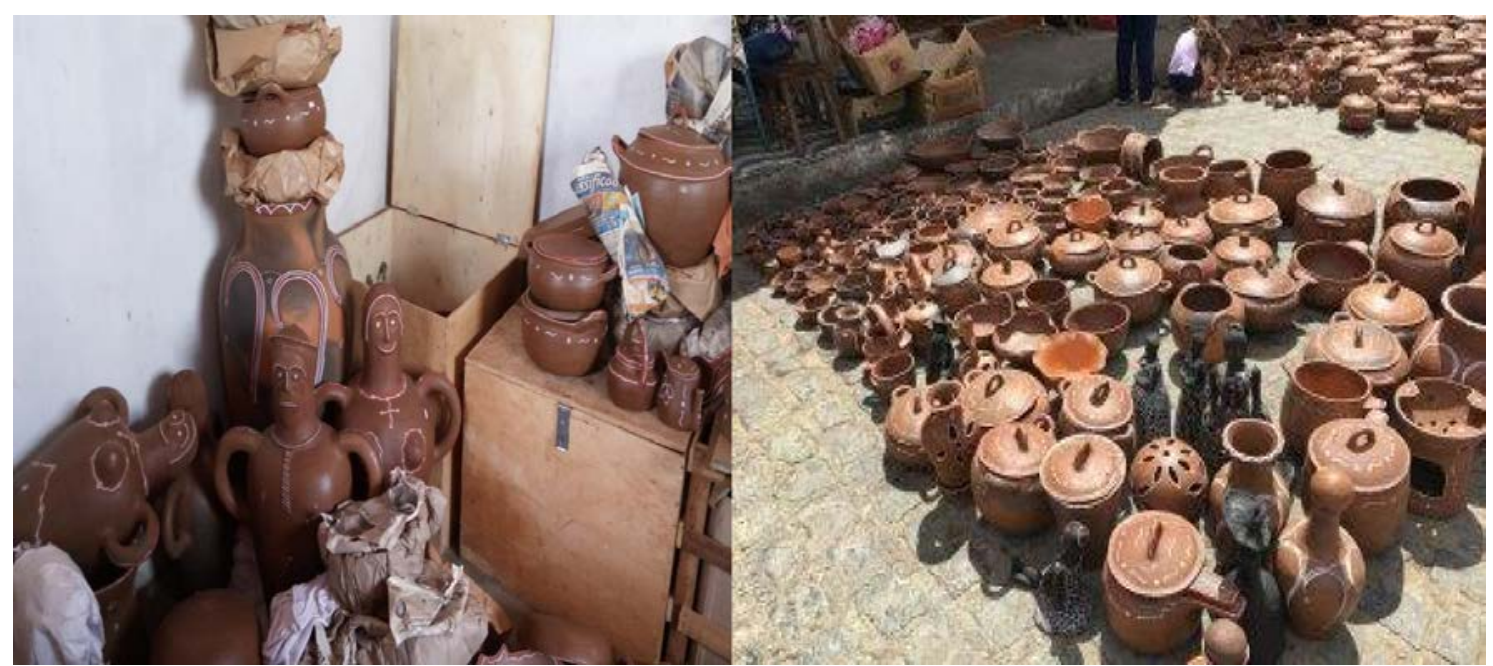

Figura 7. Estocagem e exposição em feira livre da Região do Cariri, Paraíba, Brasil.

Nesse aspecto, há de se considerar as Casas de Economia Solidária, um espaço fornecido gratuitamente pela Secretaria de Desenvolvimento Humano do Governo do Estado da Paraíba, que permite a comercialização, democrática e desburocratizada de uma série de produtos, assim como o EcoParaíba, um espaço multifuncional que agrupa 
capacitação, assessoramento e comercialização de produtos da agricultura e do artesanato paraibano, contemplando balcões de negócios da economia solidária, stands de vendas da agricultura familiar de base agroecológica e outros produtos. Esse tipo de ação poderia ser adotado no contexto municipal, o que contribuiria para otimizar e melhorar a cadeia produtiva dos produtos produzidos pelos artesãos, em nosso caso, as louceiras de barro.

Quanto a desvalorização econômica, verifica-se a insatisfação com relação ao baixo preço (barateamento) das peças e na interferência de "atravessadores". Atores que as adquirem por um preço " $\mathrm{X}$ " e as revende por um preço " $\mathrm{Y}$ ", no mínimo $100 \%$ mais caras, dentro e fora do estado da Paraíba. Além do que, a ausência de identificação própria na peça, contribui para a má fé desses atravessadores, quanto à sua autoria. A identificação dá-se apenas com pontos de tinta brancos.

Referindo-se a capacitação e apoio, inexiste totalmente, seja para o setor agropecuário sob assistência técnica, seja para atividade artesanal através de iniciativas privadas ou das gestões públicas (federal, estadual e municipal). Mas importa considerar que, embora o grupo das louceiras não esteja vinculado atualmente a nenhum sindicado ou associação, é possível reavivar o sentimento cooperativista e as boas práticas já experimentadas, contemplado por órgãos de apoio técnico e incentivo ao desenvolvimento sustentável, por meio de cursos de capacitação oferecidos pelo Serviço Brasileiro de Apoio às Micro e Pequenas Empresas (SEBRAE) e o Projeto de Desenvolvimento Sustentável do Cariri, Seridó e Curimataú (PROCASE), possibilitando, inclusive, a implantação de um projeto de marketing para os produtos e um zoneamento da produção, com a criação de um selo identificador dos "Produto das Louceiras de Serra Branca, Paraíba, Brasil", coibindo as más práticas dos atravessadores comerciais e criando uma identidade cultural.

Algumas das peças produzidas pelas louceiras do Ligeiro de Baixo são modelos de bonecas como as noivinhas, beatas, presépios, bandejas, bolas vazadas, animais, quartinhas, potes, moringas e, as tão famosas panelas, de vários tipos: cuscuzeira, panela de pressão, frigideira, fogareiros, bules, cumbucas, xícaras e pratos, todos, em tamanhos variados. Andrade-Filho (1971) defende que a cerâmica é agrupada em três grandes grupos: cerâmica utilitária simples, cerâmica utilitária figurativa e cerâmica decorativa, sendo esses três tipos identificados na comunidade estudada no presente estudo. genéricos:

Já Ribeiro (1986) propõe uma divisão mais detalhada chamada de grupos

O Grupo A, são as cerâmicas utilitárias para cozinhar e/ou frigir alimentos, como panela, tigela e assadeira. Grupo B, as cerâmicas utilitárias e/ou cerimonial para armazenar e servir alimentos, como jarra para água, jarro para cultivo de plantas, quartinha/moringa, prato e pote. 0 Grupo C, são as cerâmicas para o sustentáculo de panelas, tipo fogareiro. Já o Grupo D, são Cerâmicas estatuárias temáticofigurativa como miniaturas diversas para comércio e uso lúdico, como as miniaturas de utensílios domésticos e de componentes da fauna. Por fim, o Grupo E, que são as cerâmicas específicas para a venda, feitas por influência do contato com o mercado urbano, destinada exclusivamente ao consumo externo, a exemplo de alambique para fabrico de cachaça e peças variadas para decoração em residência urbanas como xícara, pires, bule, copo, vasos assimétricos e réplicas de cabeças humanas, entre outros (Ribeiro, 1986).

O nível e consistência do trabalho com o barro, conferido na figura 8, levou a louceira Maria José Rodrigues à conquista do 1을 lugar, na Categoria Decorativa, da peça "Simplesmente Mulher", na versão 2007 do Salão Paranaense de Cerâmica Popular e, na versão 2008, na categoria Cerâmica Popular, com a peça "O sapo" da louceira Vera Lúcia. 0 evento é realizado anualmente pelo Museu Alfredo Andersen, em Curitiba, Paraná, sendo promovido pelo Governo do Estado. 


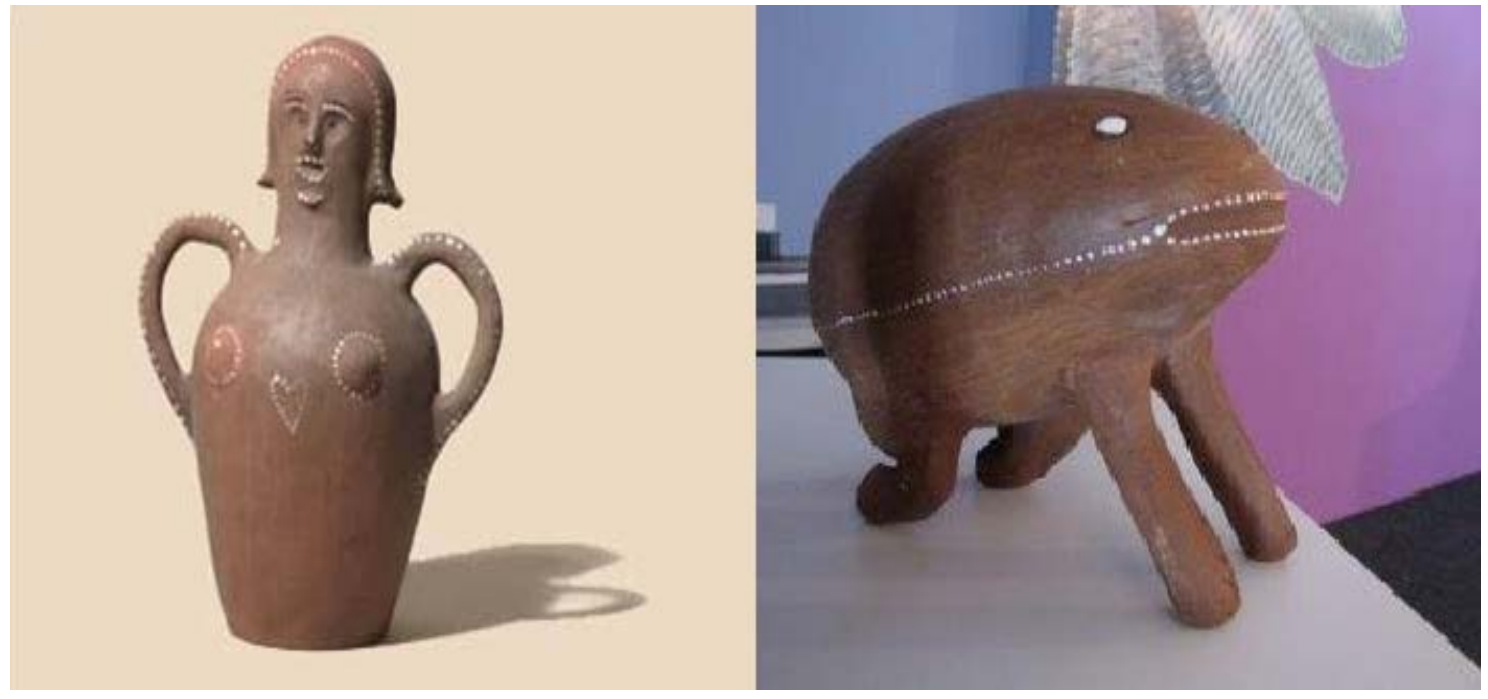

Figura 8. Boneca "Simplesmente Mulher" e “O Sapo”. Fotos: Babel das Artes (2019).

Quanto à desvalorização é importante notar que ela parte, principalmente, dos habitantes da própria região e do poder público local e regional, que não reconhecem nas panelas de barro (utilitário mais vendido), nem nas bonecas (decorativo mais vendido), uma obra de arte com valor agregado cultural. Esse reconhecimento e valorização parte, comumente, dos turistas. Nesse ponto, Canclini (2003), diz que perceber "as estratégias que os artesãos utilizam para entrar e sair da modernidade" e procurar fazer uma "hibridação" do repertório que já existia com uma "nova produção", permite que as peças sejam substituídas e/ou adequadas, com a finalidade de atender aos interesses turísticos e mercadológicos.

Nesse sentido, destaca-se a importância da escola/educação como papel fundamental, seja na conscienticialização das novas gerações quanto a sua relevância para divulgação e preservação desse patrimônio, seja em uma formação direcionada que assegure a valorização profissional dessas louceiras, até mesmo na contribuição do desenvolvimento pessoal destas, na melhoria da qualidade, da produtividade e competitividade com registro em foto e catalogação das peças e, finalmente, no reforço para (re)conhecimento, por parte da gestão, do quão é importante a consolidação e viabilização de iniciativas culturais e o desenvolvimento das artes para história de um povo.

"A escola tem que ajudar a criança para que, em seu processo de crescimento, ela vá compreendendo a realidade que a cerca e nela vá se localizando lúcida e criativamente. Este processo a inicia na realidade imediata com o meio: aprende a VER no mesmo, para em seguida estender seu olhar na direção de horizontes mais largos" (Nidelcoff, 1979).

Conforme revelado na Figura 9, percebe-se que a rotina sob sol escaldante, sem proteção adequada, com precariedade de água e o esforço físico dos movimentos constantes e repetitivos durante anos, tem acarretado problemas de saúde. As maiores dificuldades nessa variável são: dores nas costas, braços, pernas, mãos trêmulas, cãibras e rouquidão, sendo essa última, possivelmente ocasionada ou agravada pela fumaça expelida pelos fornos durante as queimas. 

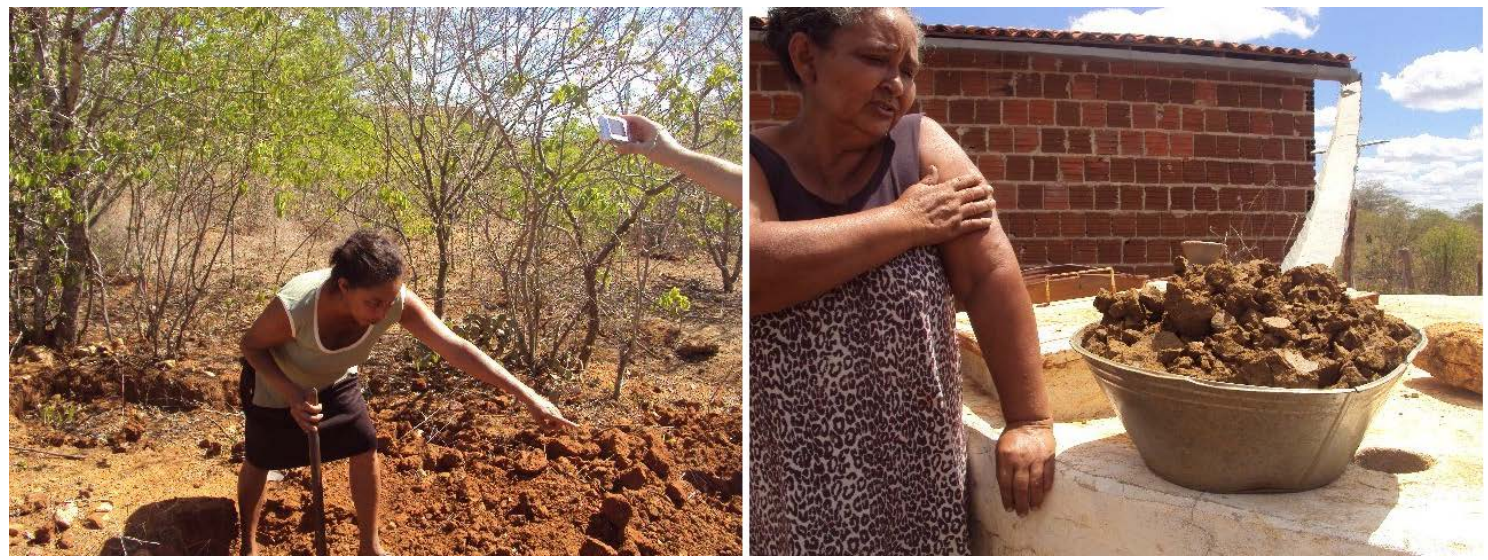

Figura 9. Reconhecimento e coleta do barro na comunidade Ligeiro de Baixo, Serra Branca, Paraíba, Brasil.

Nota-se que as variáveis limitantes no processo de continuidade e valorização da arte das louceiras de Ligeiro de Baixo, ou seja, transporte e estocagem das peças para as feiras livres, atendimento em saúde de forma preventiva e capacitação, apresentadas na Figura 10, acomodam-se em uma única variante, que é o "apoio da gestão pública".

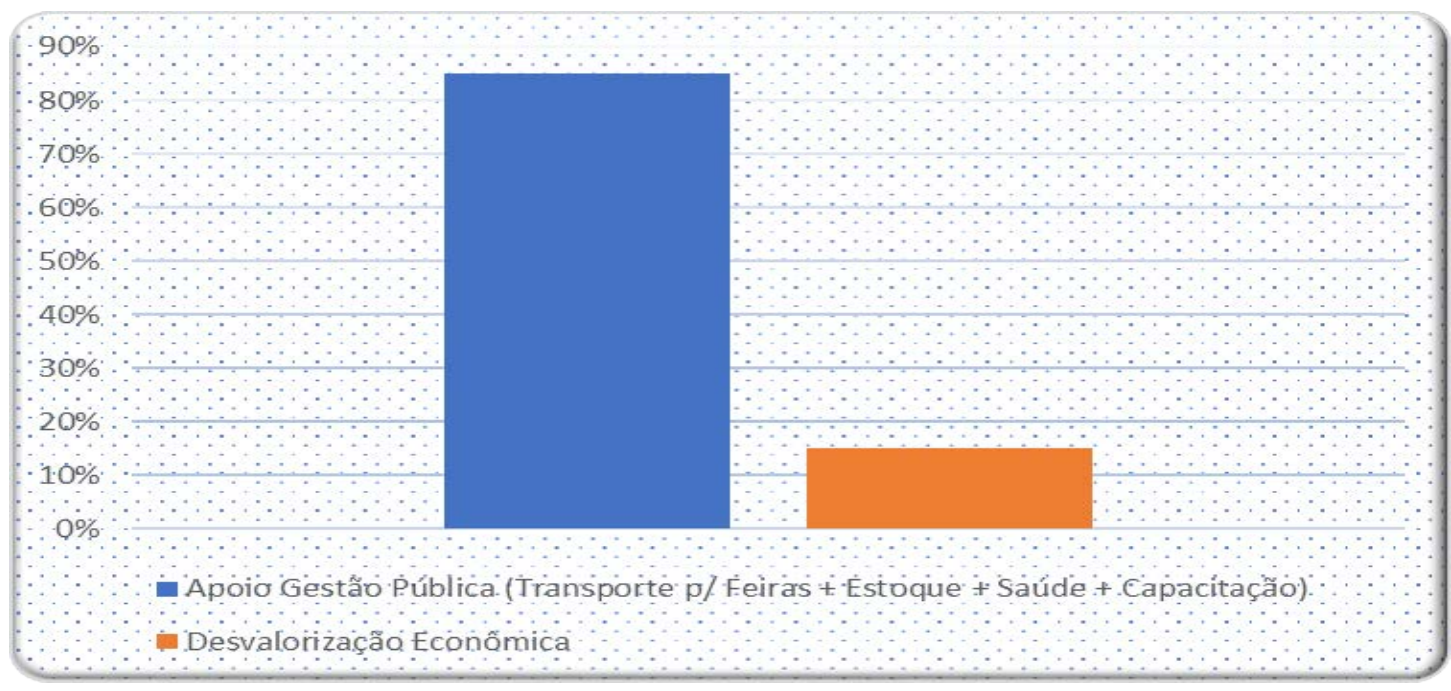

Figura 10. Variáveis de gestão, que limitam a continuidade do artesanato com louças de barro na comunidade Ligeiro de Baixo, Serra Branca, Paraíba, Brasil.

Considerando que existem normas legais e políticas públicas direcionadas à Cultura e Saúde, em todas as suas vertentes e níveis da federação, previstos na Lei $\mathrm{n}^{\mathrm{o}}$ 13.180 (Brasil, 2015), como aspectos de orientação, qualificação, estímulo ao aperfeiçoamento dos métodos e processos de produção, apoio comercial, certificação de qualidade do artesanato e sua divulgação, assim como, o direito à saúde aos cidadãos, diminuição das desigualdades e investimento nas carência e integração das ações na promoção da saúde, com prevenção de doenças, são princípios básicos do Sistema Único 
de Saúde (SUS), e devem ser cumpridas e garantida, sobretudo, com articulação de outras políticas públicas (Brasil, 2017), confere-se que a gestão municipal, não possui um conjunto de elementos exigidos pela nova administração pública, denominado de CHA (competência, habilidade e atitude). "Esses elementos têm interdependência e se complementam nas relações de trabalho, geram o desempenho profissional, exprimem os comportamentos da pessoa em suas relações laborais $e$ promovem as realizações $e$ resultados" (ENAP, 2009).

\section{Conclusões}

Percebeu-se que, as mestras do barro, adquiriram todo o conhecimento dentro da própria família, de mãe para filha, caracterizando-se como uma atividade eminentemente feminina, e que as gerações mais recentes não se interessam em dar continuidade à atividade artesanal da louça de barro, embora, detentoras deste mesmo conhecimento, seja pelo esforço físico em uma região de sol escaldante e escassez de água, seja pela falta de reconhecimento cultural e artístico da região e, principalmente, pelo pouco retorno econômico/financeiro.

0 conhecimento das louceiras sobre o solo, percebeu-se pela abordagem etnopedológica, através das informações diversificadas e contextualizadas relacionadas não somente ao solo, mas também aos aspectos relacionados com esta tradição nesta comunidade, reafirmando que as peças são mais que simples objetos de barro vistos em feiras e casas, mas um legado que reflete um conjunto de relações familiares materiais e espirituais em uma dinâmica que envolve a louceira, sua técnica, o material e os objetos produzidos.

As louceiras não identificam o solo pelo nome cientifico e sim pela cor, sendo o principal material utilizado o barro vermelho ou barro de louça, misturado a um barro mais claro, sentido entre os dedos indicador e polegar como forma de identificar sua qualidade e a "liga".

As principais peças produzidas são as decorativas e utilitárias, destinadas às feiras livres da região do Cariri ocidental e oriental paraibano, embora exista a presença de atravessadores que, adquirem as peças por um valor e as revendem em outras cidades e Estados, por outro valor bem superior.

Não existem políticas públicas da gestão municipal direcionadas à essa atividade, ainda que exista vários canais de apoio e facilitação da gestão estadual.

Aproveitam, para queima nos fornos, galhos secos caídos no chão, evitando desmatamento, utilizando-se assim, dos próprios sistemas de manejo do solo, da água e da vegetação, decorridos dos conhecimentos e experiências acumuladas, lidando com os recursos naturais de forma correta e sustentável e com impactos mínimos ao meio ambiente.

As peças, em sua grande maioria, não possuem identificação ou assinatura própria, apenas alguns pontos de tinta branca, o que contribui para ação dos atravessadores e para desvalorização da peça em sua fonte.

Apesar da forte possibilidade dessa tradição se perder, em virtude das dificuldades já impostas pela natureza, a falta de entusiasmo dos jovens da comunidade e a ausência de apoio e incentivo por meio de políticas públicas, as louceiras entrevistadas manifestam o desejo de manter viva essa tradição, a fim de conservar a tradição e empoderar a sociedade com seus conhecimentos tradicionais, preservando a história cultural da arte com barro. 


\section{Agradecimentos}

Ao biólogo Ezequiel da Costa Ferreira, pela confecção dos mapas. As loucerias da comunidade rural Ligeiro de Baixo, município de Serra Branca, Estado da Paraíba, Nordeste do Brasil. Ao Programa de Pós-Graduação em Desenvolvimento e Meio Ambiente (PRODEMA), da Universidade Federal da Paraíba (UFPB), pela possibilidade do desenvolvimento dessa pesquisa como parte do mestrado da autora Ana Paula Gonçalves Leite. À Universidade Federal de Campina Grande pelo apoio condedido pelo Centro de Desenvolvimento Sustentável do Semiárido, localizado no Município de Sumé.

\section{Conflito de interesses}

Os autores declaram não haver conflito de interesses.

\section{Referências}

Albuquerque, U. P.; Lucena, R. F. P. e Cunha, L. V. F. C. (Eds.). Métodos e técnicas na pesquisa Etnobiológica e Etnoecológica. Editora NUPEEA, Recife, 2010.

Almeida, L. S. D. As ceramistas indígenas do São Francisco. Estudos Avançados, v. 17, n. 49, p. 255-270, 2003. https://doi.org/10.1590/S0103-40142003000300015

Andrade-Filho, O. D. Normas para pesquisa da cerâmica. Rio de Janeiro: Ministério da Educação e Cultura, 1971. (Campanha de Defesa do Folclore Brasileiro).

Babel das Artes. 2019. Disponível em: <http://www.babeldasartes.com.br>. Acesso em: 22 fev. 2019.

Bailey, K. D. Methods of social research. 4. ed. New York: Free Press, 1994.

Barrera-Bassols, N.; Toledo, V. M. Ethnoecology of the Yucatec Maya: Symbolism, knowledge and management of natural resources. Journal of Latin American Geography, v. 4, n. 1, p. 9-41, 2005.

Basher, L. R. Is pedology dead and buried? Australian Journal of Soil Research, v. 35, n. 5, p. 979-994, 1997. https://doi.org/10.1071/S96110

Borges, K. V. O. As mulheres ceramistas do Mocambo: a arte de viver de artefatos ambientais. Manaus: Universidade Federal do Amazonas, 2017. (Tese de doutorado).

Brandão, C. R. 0 ambiente, o sentimento e o pensamento: dez rascunhos de idéias para pensar as relações entre eles e o trabalho do educador ambiental. Anais do Fórum de Educação Ambiental, Rio de Janeiro, 1997.

Brasil. Lei no 10.741, de 1o de outubro de 2003. Dispõe sobre o Estatuto do Idoso e dá outras providências. Disponível em: <http://www.planalto.gov.br/ccivil_03/leis/2003/ 110.741.htm>. Acesso em: 21 ago. 2018.

Brasil. Lei no 13.180, de 22 de outubro de 2015. Dispõe sobre a profissão de artesão e dá outras providências. Disponível em: <http://www.planalto.gov.br/ccivil_03/_ato20152018/2015/lei/l13180.htm>. Acesso em: 21 ago. 2018.

Brasil. Ministério da Agricultura. Levantamento exploratório: reconhecimento dos solos do Estado da Paraíba. Rio de Janeiro: Ministério da Agricultura, 1972.

Brasil. Ministério da Saúde. Sistema Único de Saúde (SUS). 2017. Disponível em: <http://portalms.saude.gov.br/sistema-unico-de- saude/principios-do-sus>. Acesso em: 21 ago. 2018. 
Brasil. Portaria SCS/MDIC no 29, de 05 de outubro de 2010. Torna pública a base conceitual do artesanato brasileiro para padronizar e estabelecer os parâmetros de atuação do Programa do Artesanato Brasileiro - PAB em todo o território nacional. Disponível em: <https://www.legisweb.com.br/legislacao/?id=221568>. Acesso em: 21 ago. 2018.

Brasil. Resolução CNS no 466, de 12 de dezembro de 2012. Disponível em: <https://bvsms.saude.gov.br/bvs/saudelegis/cns/2013/res0466_12_12_2012.html>. Acesso em: 21 ago. 2018.

Cabral, R. L. Uso e conhecimento do solo por artesãos camponeses no Agreste Pernambucano: uma abordagem etnopedológica. Recife: Universidade Federal de Pernambuco, 2011. (Dissertação de mestrado).

Cabrera-Garcia, S. La alfarería popular de El Cercado (La Gomera). La Laguna (Tenerife): Centro de la Cultura Popular Canaria - IPRECAN, 1996.

Canclini, N. G. Culturas híbridas: estratégias para entrar e sair da modernidade. São Paulo: EDUSP, 1997.

Carvalho, T. K. N.; Sousa, R. F.; Meneses, S. S. S.; Ribeiro, J. P. O.; Felix, L. P.; Lucena, R. F. P. Plantas usadas por uma comunidade rural na Depressão Sertaneja no Nordeste do Brasil. Biofarma,v. esp., p. 92-120, 2012.

CIEGESI - Conferência Internacional de Estratégia em Gestão, Educação e Sistemas de Informação. Goiânia Disponível em: <http://www.anais.ueg.br/index.php/ciegesi/article/ view/781/820> Acesso em: 21 ago. 2018.

EMBRAPA - Empresa Brasileira de Pesquisa Agropecuária. Sistema Brasileiro de Classificação de Solos. 2. ed. Brasília: Embrapa Produção de Informação; Rio de Janeiro, Embrapa Solos, 2013.

ENAP - Escola Nacional de Administração Pública. Gestão por competências. Brasília: ENAP, 2009. Disponível em: <http://www.drbassessoria.com.br/12gestaopor competencias.pdf $>$. Acesso em: 21 ago. 2018.

Huntington, H P. Using traditional ecological knowledge in science: methods and applications. Ecological Applications, v. 10, n. 5, p. 1270-1274, 2010. https://doi.org/ 10.1890/1051-0761(2000)010[1270:UTEKIS]2.0.CO;2

IBGE - Instituto Brasileiro de Geografia e Estatística. 2017. Disponível em: $<$ http://cidades.ibge.gov.br/xtras/temas.php?lang=\&codmun=250073\&idtema=156\&sear ch=p araiba| serrabranca -2017>. Acesso em: 21 ago. 2018.

IDEME - Instituto de Desenvolvimento Municipal e Estadual da Paraíba. Índice de Desenvolvimento Humano no Brasil. 2013. Disponível em: $<$ http://ideme.pb.gov.br/servicos/perfis-do-idhm/atlasidhm2013_perfil_serrabranca _pb.pdf>. Acesso em: 21 ago. 2018.

Kickert, W.; Stillmann, J. M. (Eds.). The modern state and its study: New administrative sciences in a changing Europe and United States. Cheltenham, UK; Northampton, MA: Edward Elgar, 1999.

Matias-Pereira, J. Manual de gestão pública contemporânea. 3. ed. São Paulo: Atlas, 2010.

Minami, K. Soil and humanity: Culture, civilization, livelihood and health. Soil Science and Plant Nutrition, $\quad$ v. 55, p.603-615, 2009. https://doi.org/10.1111/j.17470765.2009.00401.x 
Nidelcoff, M. T. A escola e a compreensão da realidade. São Paulo: Brasiliense, 1979.

Paraíba. Relatório do Zoneamento Agropecuário do Estado da Paraíba. João Pessoa: Universidade Federal da Paraíba; Fundação de Pesquisa e Extenção - FUNAPE; Centro de Ciências e Tecnologia - CCT; Centro de Ciências Agrárias - CCA, 1978.

Santos, J. Relações de género e produção de cerâmica na comunidade de quilombola de Olaria, em Irará-Bahia. Revista Latino-americana de Geografia e Género, v. 1, p. 134-147, 2010. https://doi.org/10.5212/Rlagg.v.1.i1.134147

Serra Branca. História da cidade. Serra Branca: Prefeitura Municipal. 1991. Disponível em: <http://www.serrabranca.pb.gov.br/acidade/historia>. Acesso em: 21 ago. 2018.

Sumé. Decreto no 340, de 3 de julho de 1991. Dispõe sobre o regulamento da Filarmônica Municipal "Maestro Antônio Josué de Lima”. Sumé, Paraíba.

Turchetti, N. G. "A história em cacos": A cultura material Jê pré-colonial - Sítio Lito-Cerâmico Mato Seco, São Gonçalo do Abaeté, Minas Gerais. São João Del-Rei: Universidade Federal de São João Del-Rei, 2018. (Dissertação de mestrado).

Vital, A. F. M.; Santos, R. V. Solos, da educação à conservação: ações extensionistas. Maceió: Tegraf, 2017.

Informação da Licença: Este é um artigo Open Access distribuído sob os termos da Licença Creative Commons Attribution, que permite uso irrestrito, distribuição e reprodução em qualquer meio, desde que a obra original seja devidamente citada. 